\section{Reduced Water Permeability of Biodegradable PCL Nanocomposite Coated Paperboard Packaging*}

\author{
J. Bota, ${ }^{a,{ }^{* *}}$ M. Vukoje, ${ }^{a}$ M. Brozović, ${ }^{a}$ and Z. Hrnjak-Murgić \\ ${ }^{a}$ Faculty of Graphic Arts, University of Zagreb, \\ Getaldićeva 2, 10000 Zagreb, Croatia \\ ${ }^{b}$ Faculty of Chemical Engineering and Technology, \\ University of Zagreb, Marulićev trg 19, 10000 Zagreb, Croatia
}

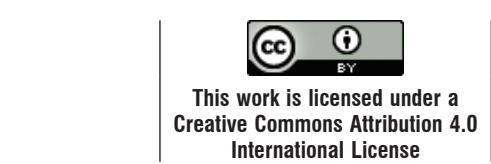

doi: 10.15255/CABEQ.2017.1126

Original scientific paper Received: March 23, 2017 Accepted: November 6, 2017

In this work, we studied the properties of printed paperboard samples coated with biodegradable PCL polymer, which was considered to overcome the disadvantages (barrier properties) of a paper-based material. Additionally, the samples were coated with PCL modified with $\mathrm{SiO}_{2}$ and $\mathrm{Al}_{2} \mathrm{O}_{3}$ nanoparticles. The characterization of the coated paperboard (with print) samples was made by determination of water vapor transmission rate (WVTR), contact angle of water and its evolution over time, and mechanical and visual properties. The samples were also examined by SEM microscopy. The results show that PCL and PCL coatings modified with $\mathrm{SiO}_{2}$ and $\mathrm{Al}_{2} \mathrm{O}_{3}$ nanoparticles slow down the water vapor transmission rate when compared to the paperboard without coatings. The water contact angle measurements show an increase in hydrophobicity in paperboard coated with PCL-SiO , while PCL- $\mathrm{Al}_{2} \mathrm{O}_{3}$ shows a decrease when compared to neat paperboard and paperboard coated with neat PCL. The studied coated samples also improve mechanical properties of paperboard while preserving the visual properties of print.

Key words:

paperboard packaging, water permeability, nanocomposite, biodegradable polymer

\section{Introduction}

Paper-based packaging materials have a major share in the packaging industry, as well as the use of synthetic polymers. Due to some weaker properties of paperboard, synthetic polymers have grown and continue to grow in packaging production ${ }^{1}$. The main disadvantages of synthetic polymer packaging materials are recyclability and stability to biodegradation.

Paper-based packaging materials are environmentally friendly due to recyclable and compostable properties, but are often not suitable as a packaging material since they have poor barrier properties, for example, against moisture. When stored under high humidity conditions or when in contact with high-moisture materials, they tend to absorb water vapour from the environment due to cellulose composition resulting in their reduced physical and mechanical strength ${ }^{2}$. The design of water-repellent barrier layers is essential for packaging materials

"Presented at the " 4 th International Symposium on Environmenta Management - Towards Circular Economy (SEM2016), December 7 - 9, Zagreb, Croatia"

${ }^{* *}$ Corresponding author: e-mail josip.bota@grf.hr made from porous and absorbent textiles, paper or paperboard ${ }^{3}$. Low barrier abilities against water vapor and gases are the main problems in food packaging. In order to extend the product's shelf life, it is essential to modify and improve these properties.

The surface of a paper can be coated with thin polymer layer that contains required properties: physical strength, oil/grease resistance, wettability, smoothness and/or good optical properties.

Recently, biodegradable polymers are increasingly applied as coating materials. The surface properties and wettability of those substrates can be influenced by physical (drying, calendaring) and chemical (impregnation, coating) treatments, forming a first barrier against water adsorption. Hydrophobic barrier coatings are most likely applied by means of extrusion, lamination or dispersion coating $^{3}$. Many biopolymers are hygroscopic materials and can lose their barrier properties at high relative humidity (RH) due to water absorption ${ }^{4}$. PCL is a biopolymer with low water vapor transmission rate and has been used as a film on different materials ${ }^{5}$, Barrier properties can be additionally improved with the usage of different inorganic nanofillers for reinforcement, such as $\mathrm{SiO}_{2}, \mathrm{Al}_{2} \mathrm{O}_{3}, \mathrm{ZnO}, \mathrm{TiO}_{2}$, etc. Besides the barrier properties, these inorganic nano- 
fillers can affect mechanical properties as well. Physical properties are largely dependent on the degree of nanoparticles dispersion in polymer matrices, mainly mechanical and rheological properties. Depending on the polymer matrix and used nanofillers, nanocomposites may display different properties. The addition of nanoparticles in matrix mostly affects thermal stability, elastic modules, tensile and yield strength, melting temperature and degree of crystallinity ${ }^{6-9}$. The absence of chemical bonding between the polymer and the particle can influence the mechanical properties of composites because a strong interfacial bonding can effectively transfer the load from the matrix to the reinforcement. Besides mechanical properties, biodegradation study of PCL/silica nanocomposite showed that biodegradation rates have been enhanced in the PCL/silica nanocomposites compared to neat $\mathrm{PCL}^{6}$.

Modification of optical and radiative properties of composites with the use of "classic" nano-oxide particles (silica, alumina, zirconia) appears promising for the reinforcement of transparent polymers. In general, these are quasi-spherical nanoparticles used in transparent materials to prevent the diffusion phenomena ${ }^{10}$. Aluminium oxide coatings on polymers are widely used to improve the gas barrier properties of polymers in the packaging ${ }^{4}$. Alumina particles are used as fillers in a wide range of sizes, from $20 \mathrm{~nm}$ to micrometric sizes. They are frequently used as inert fillers in polymers, but highlight catalytic properties in some conditions ${ }^{10}$.

Silica nanoparticles have many advantages, including high mechanical strength, permeability, thermal and chemical stability, a relatively low refractive index and high surface area. Their incorporation into polymer films is also known to enhance the film mechanical properties and reduce its thermal degradation at high temperature, as well as increase the barrier properties to solvents and volatile products ${ }^{11}$. Silica nanofiller incorporated in polymer composites can be used for enhancement of viscosity in paints, adhesives, etc ${ }^{12}$. It is important to mention that high content of nanofillers can result in high density and poor mechanical properties of polymers ${ }^{13}$. The addition of $0.05 \mathrm{wt} \%$ of silica nanofillers improved mechanical properties due to their good dispersion in PLA matrix. With increasing silica content, the tensile strength and elongation at break were decreased ${ }^{14}$.

The aim of this study was to decrease permeability and increase mechanical properties of paperboard using PCL polymer modified with $\mathrm{SiO}_{2}$ and $\mathrm{Al}_{2} \mathrm{O}_{3}$ nanoparticles while keeping its biodegradability. Also, the effects of the nanocomposite coatings were analyzed to ensure the color change is acceptable for use after print.

\section{Materials and methods}

\section{Materials}

Being a common material in the packaging industry, Umka color $^{\circledR} 230 \mathrm{~g} \mathrm{~m}^{-2} \mathrm{GD} 2$ paperboard $(\mathrm{K} / 0)$ was used and cut into $30 \mathrm{~cm} \times 35 \mathrm{~cm}$ sheets samples. Offset printed with CMYK colors Novavit ${ }^{\circledR}$ F 918 SUPREME BIO, light fastness C-8, M-5, Y-5, K-8. The coating was prepared from polycaprolactone (PCL) biopolymer (molecular mass: Mn 80,000) Aldrich $^{\circledR}$. Hydrophobic fumed silica, mean primary particle size 5 to $50 \mathrm{~nm}, \mathrm{SiO}_{2}$ content $>99.8 \%$, specific surface area (BET) $220 \pm 25$ $\mathrm{m}^{2} \mathrm{~g}^{-1}$, and aluminum oxide (AEROXIDE® Alu C), nanopowder, $13 \mathrm{~nm}$ primary particle size (TEM), $\mathrm{Al}_{2} \mathrm{O}_{3}$ content $>99.8 \%$ specific surface area (BET) $100 \pm 15 \mathrm{~m}^{2} \mathrm{~g}^{-1}$, were used as the nanofillers. The ethyl-acetate solvent $\left(\mathrm{C}_{4} \mathrm{H}_{8} \mathrm{O}_{2}\right)(99.5 \%)$ (T.T.T. d.o.o. $\left.{ }^{\circledR}\right)$ was used for the coating preparation.

\section{Print sample preparation}

The examined colors were basic colors of subtractive color synthesis and key black (CMYK). Color test card was prepared via X-rite Color Port ${ }^{\mathbb{B}}$ software and exported as a TIFF file (Fig. 1). Prepress was sent to be printed with implemented Process Standard Offset printing developed by Fogra ${ }^{\circledR}$ (ISO 12647-2) to ensure good print quality using CMYK ink Novavit ${ }^{\circledR}$ F 918 SUPREME BIO.

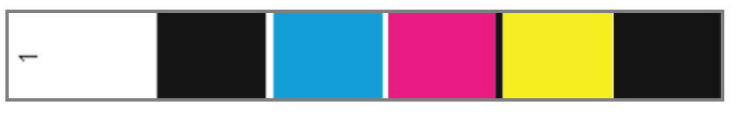

Fig. 1 - Color test card

\section{Coating preparation}

The coating was prepared by dissolving $10 \mathrm{~g}$ of PCL polymer granulates in $90 \mathrm{~g}$ of ethyl-acetate solvent. The solution was then heated at $40{ }^{\circ} \mathrm{C}$ and stirred 30 min to obtain a homogeneous $10 \%$ solution. The coatings on the printed color test card samples from PCL polymer solution were prepared by varying the concentrations of silica nanoparticles. Four different coatings were prepared, neat PCL $(\mathrm{K} / \mathrm{P})$ and by adding $2 \mathrm{wt} . \% \mathrm{SiO}_{2}(\mathrm{~K} / \mathrm{P} / 2 \mathrm{Si}), 1$ wt. $\% \mathrm{Al}_{2} \mathrm{O}_{3}(\mathrm{~K} / \mathrm{P} / 1 \mathrm{Al})$ and 2 wt. $\% \mathrm{SiO}_{2}$ with 0.5 wt. $\%\left(\mathrm{~K}^{2} / \mathrm{P} / 2 \mathrm{Si} / 05 \mathrm{Al}\right)$; dispersing them with a homogenizer for $8 \mathrm{~min}$ at $15000 \mathrm{rpm}$. Unwanted solvent evaporation was controlled by sealing the container using paraffin strips, and the mass of the solution was compared before and after the procedure.

\section{Coating application}

The coating was applied using the K202 Control Coater in controlled conditions defined by the ISO 187:1990 standard. The wet coating thickness 
was defined with the standard coating bars to $24 \mu \mathrm{m}$ (dry coating $\sim 6 \mu \mathrm{m}$ ). All coatings were applied on the printed side of the paperboard, and designated according to Table 1 .

Table 1 -Composition of PCL nanocomposites (wt.\%) and designation

\begin{tabular}{lcc|c|c}
\hline \multicolumn{1}{c|}{ Sample } & $\mathrm{E}-\mathrm{A}$ & $\mathrm{P}$ & $\mathrm{Al}$ & $\mathrm{Si}$ \\
\hline $\mathrm{K} / 0$ & - & - & - & - \\
$\mathrm{K} / \mathrm{P}$ & 90 & 10 & - & - \\
$\mathrm{K} / \mathrm{P} / \mathrm{Al}$ & 89 & 10 & 1 & - \\
$\mathrm{K} / \mathrm{P} / 2 \mathrm{Si}$ & 88 & 10 & - & 2 \\
$\mathrm{~K} / \mathrm{P} / 2 \mathrm{Si} / 05 \mathrm{Al}$ & 87.5 & 10 & 0.5 & 2 \\
\hline $\mathrm{K}-$ paperboard, E-A - ethyl acetate, $\mathrm{P}-\mathrm{PCL}, \mathrm{Al}-\mathrm{Al}_{2} \mathrm{O}_{3}$, \\
$\mathrm{Si}-\mathrm{SiO}_{2}$
\end{tabular}

\section{Methods}

\section{Scanning electron microscopy}

The surface of a paperboard coated with PCL nanocomposites was observed with a SEM microscope (Tescan VEGA 3) $20 \mathrm{kV}$. Before examining, the samples were sputter coated with a thin layer of $\mathrm{Pt} / \mathrm{Pd}$.

\section{Water vapor transmission rate}

The water vapor transmission rate (WVTR) of a paperboard coated with PCL and PCL nanocomposites was carried out on the Herfeld's appliance. Herfeld's device consists of a glass container with a metal lid containing a circular hole of $36 \mathrm{~mm}$ in diameter. Fifty milliliters of water was poured into the glass vessel. The studied material pattern was placed (face down) on the cover of the vessel of circular diameter of $55 \mathrm{~mm}$ and the lid was closed and tightened. The device was placed in a desiccator with $97 \%$ of sulphuric acid. The weight of the apparatus with the specimen and the water was determined at the beginning and after the given time interval of 24 and $48 \mathrm{~h}$ using equation 1 . The results are presented as a mean $\pm \mathrm{SD}$ of 5 measurements per sample.

Water vapor transmission (WVTR) was determined according to equation 1 :

$$
\mathrm{WVTR}=m_{0}-\left(m_{2}-m_{3}\right) / 2
$$

$m_{0}$ - mass of the device with water and specimen at the beginning (g); $m_{2}$ - mass of the device with water and a test tube after $24 \mathrm{~h}(\mathrm{~g}) ; m_{3}$ - mass of the device with water and a test tube after $48 \mathrm{~h}(\mathrm{~g})$.

\section{Contact angle and water wettability}

Contact angle of neat paperboards and paperboards coated with PCL nanocomposite were carried out using contact angle method on Data Phys- ics OCA 20 Instrument. The contact angles of water (as the test liquid) on the coated paperboards was measured at $23{ }^{\circ} \mathrm{C} \pm 0.2$ and humidity of $60 \% \mathrm{RH}$, and the drop volume was $2 \mu \mathrm{L}$ and measured over a time-span of $6 \mathrm{~s}$. The drop shapes were geometrically determined from Laplace-Young fitting integrated into the software (SCA20, version 2.01). The examined contact angles are presented as a mean of 10 measurements per sample type.

\section{Bursting strength}

Bursting strength (P) was measured using Lorentzen \& WETTRE Bursting Strength Tester (ISO 2758:2001), to determine the strength of paperboard samples. Dimensions of the tested paperboard specimen were $d=100 \mathrm{~mm}$, measuring range $d=50$ $\mathrm{mm}$, and the device diaphragm had a diameter $d=$ $33.1 \mathrm{~mm}$. The number of samples were determined according to ISO 2758:2001.

\section{Colorimetry}

The Color test on the printed color test card samples was carried out by spectrophotometric software, the X-Rite i1 Pro $2^{\circledR}$ spectrophotometer. The results of printed paperboard test card were measured before and after coating. The averages of ten measurements per sample are presented in the results. The spectrometric values were converted to the CIE Lab color space and the color change was expressed using $\Delta E_{00}$ formula, which has been reviewed by several authors and confirmed as the one to be used when selecting a conventional color difference formula for predicting color difference involving different magnitudes ${ }^{15}$.

Color difference $\left(\Delta E_{00}\right)$ was determined according to equation 2 :

$$
\begin{aligned}
& \Delta E^{*}{ }_{00}=\left[\left(\Delta L^{*} / k_{L} S_{L}\right)^{2}+\left(\Delta C^{*} / k_{C} S_{C}\right)^{2}+\left(\Delta H^{*} / k_{H} S_{H}\right)+\right. \\
& \left.+R_{T}\left(\Delta C^{*} / k_{C} S_{C}\right)\left(\Delta H^{*} / k_{H} S_{H}\right)\right]^{1 / 2} \\
& \Delta a^{*}=a_{1}{ }^{*}-a_{2}{ }^{*} \\
& \Delta b^{*}=b_{1}{ }^{*}-b_{2}{ }^{*} \\
& \Delta C_{a b}=\left[\left(a_{2}-a_{1}\right)^{2}+\left(b_{2}-b_{1}\right)^{2}\right]^{1 / 2}=C_{1}{ }^{*}-C_{2}{ }^{*} \\
& \Delta H^{*}=\left(\Delta a^{* 2}+\Delta b^{* 2}-\Delta C^{*}{ }_{a b}^{2}\right)^{1 / 2} \\
& \Delta L^{*}=L_{2}{ }^{*}-L_{1}{ }^{*}
\end{aligned}
$$

$L-$ CIELab color space coordinate value (lightness value); $a, b-C I E L a b$ color space coordinates; $R_{T}-$ A hue rotation term to deal with the problematic blue region (hue angles in the neighborhood of $275^{\circ}$ ) Compensation for neutral colors (the primed values in the $\mathrm{L}^{*} \mathrm{C}^{*} \mathrm{~h}$ differences); $S_{L}$ - compensation for lightness $=1 ; S_{C}$ - compensation for chroma = $1+K_{1} C_{1}^{*} ; S_{H}-$ compensation for hue $=1+K_{2} C_{1}$; $K_{1}-$ graphic arts $=0.045 ; K_{2}-$ graphic arts $=0.015$. 


\section{Results and discussion}

\section{Contact angles analysis}

Contact angles of water on paperboard and PCL coated paperboards surfaces were used to determine wetting and water absorbency during time evolution. The static contact angles on paperboard coated with modified PCL coating are presented in Fig. 2, measured over sampling time of $6 \mathrm{~s}$. The higher contact angles are seen in polar liquids and hydrophobic surfaces and vice versa. Both samples which contain $\mathrm{SiO}_{2}$ nanoparticles showed hydrophobic properties, while $\mathrm{Al}_{2} \mathrm{O}_{3}$ showed much lower contact angles $\left(72^{\circ}\right)$. The highest hydrophobicity was obtained for the PCL coating modified with a combination of $\mathrm{SiO}_{2}$ and $\mathrm{Al}_{2} \mathrm{O}_{3}$ nanoparticles $\left(91^{\circ}\right)$, followed by $\mathrm{SiO}_{2}\left(8^{\circ}\right)$. PCL samples showed similar contact angle of water as neat GD2 paperboard. The obtained results of contact angles during time of $6 \mathrm{~s}$ clearly indicate the difference in initial contact angle of water on each coated paperboard sample and the difference in the degree of decrease in contact angle with time. For uncoated paperboard, the water contact angle decreased by $18 \%$. That was the highest variation compared to other coated paperboard samples and was caused by the water absorption of the paperboard. Paperboard coated with unmodified PCL showed decrease in water contact angle by $6.6 \%$. When it comes to PCL modified with nanoparticles, the highest decrease was observed in PCL coating modified with a combination of $\mathrm{SiO}_{2}$ and $\mathrm{Al}_{2} \mathrm{O}_{3}$ (7.1\%), followed by $\mathrm{Al}_{2} \mathrm{O}_{3}(5.6 \%)$. The smallest change in water contact angle was observed for paperboard coated with $\mathrm{SiO}_{2}(4.4 \%)$. Even though the highest initial degree of water contact angle was observed for PCL modified with combination of $\mathrm{SiO}_{2}$ and $\mathrm{Al}_{2} \mathrm{O}_{3}$ nanoparticles, the changes in degree over time are greater when compared to other samples. This can be explained by the nanoparticles agglomeration and increase in the surface roughness, which can be seen

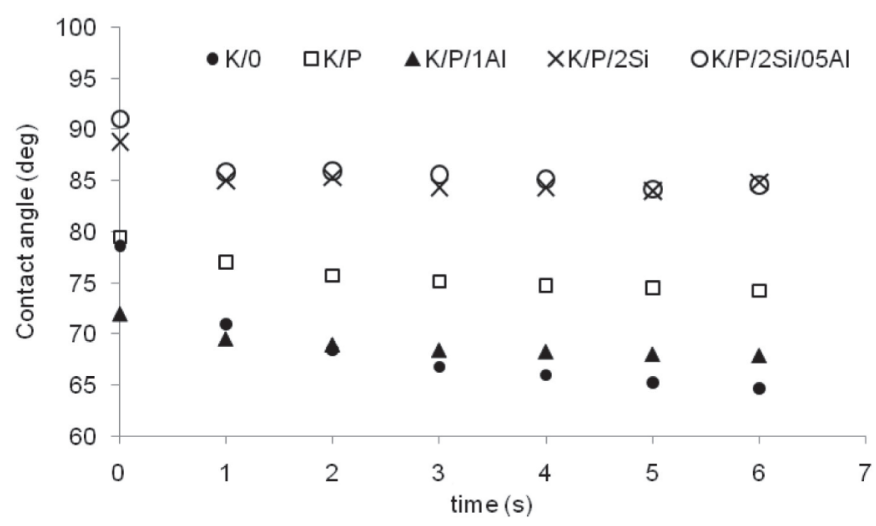

Fig. 2 - Static water contact angles measured over time evolution of $6 \mathrm{~s}$ on the SEM micrograph (Fig. 3). The change in contact angle with time can be used as an indication of the water absorption rate by the paperboards.

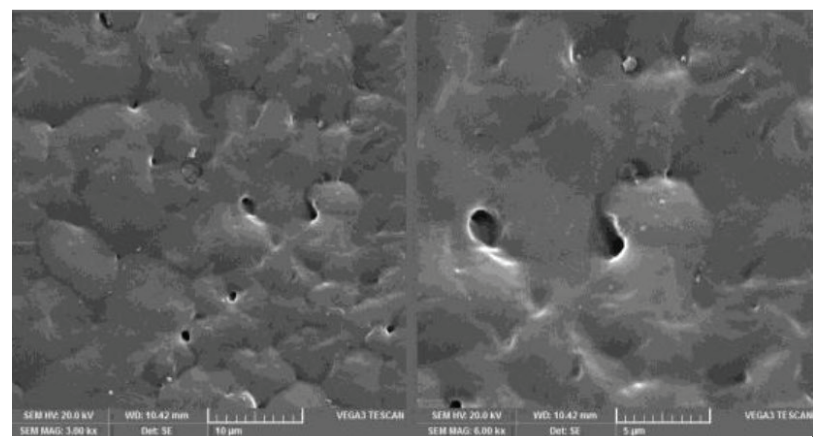

a) $\mathrm{K} / \mathrm{P}$

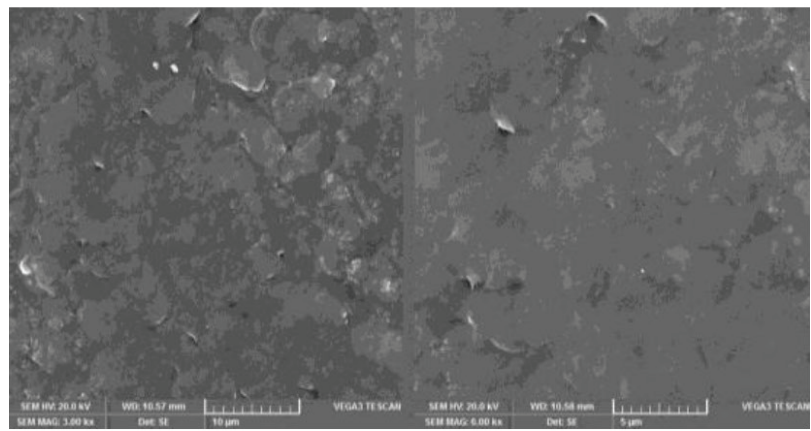

b) $\mathrm{K} / \mathrm{P} / 1 \mathrm{Al}$

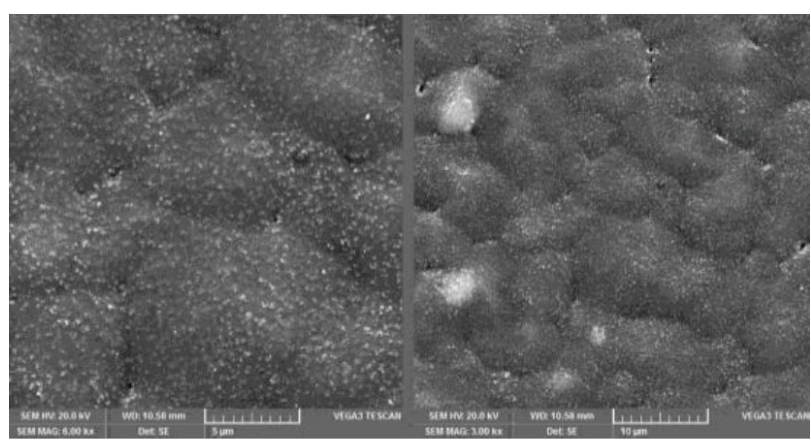

c) $\mathrm{K} / \mathrm{P} / 2 \mathrm{Si}$

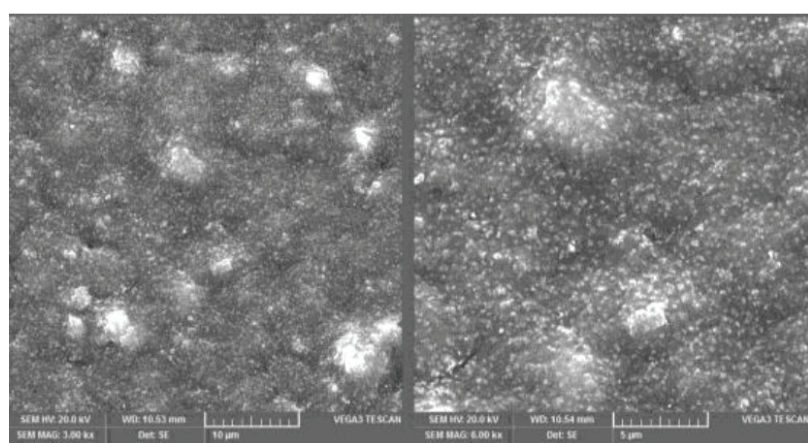

d) $\mathrm{K} / \mathrm{P} / 2 \mathrm{Si} / 05 \mathrm{Al}$

Fig. 3 - SEM micrographs of paperboard samples coated with PCL and modified with $\mathrm{SiO}_{2}$ and $\mathrm{Al}_{2} \mathrm{O}_{3}$ nanoparticles 


\section{SEM analysis}

The morphology of PCL nanocomposite coatings were analyzed with SEM micrographs and are presented in Fig. 3. PCL coating in Fig. 3(a) shows some holes approx. $2 \mathrm{~mm}$ in size, which can indicate porosity. This is explained by a lack of interaction between PCL and printed paperboard. On the other hand, morphology of the PCL nanocomposite coatings significanly differs by exhibiting more uniform coatings. PCL modified with $\mathrm{Al}_{2} \mathrm{O}_{3}$ nanoparticles seen in Fig. 3(b) shows no aggregations or holes even with 6000x magnification. Fig. 3(c) shows a very homogeneous dispersion of $\mathrm{SiO}_{2}$ with some aggregates observed in higher magnification, presented as bright circles. The good dispersion of individual $\mathrm{Al}_{2} \mathrm{O}_{3}$ nanoparticles can be explained due to its polarity. $\mathrm{PCL}$ and $\mathrm{Al}_{2} \mathrm{O}_{3}$ are polar compounds, and this results in a fully homogeneous coating. Samples that were prepared with the combination of $\mathrm{Al}_{2} \mathrm{O}_{3}$ and $\mathrm{SiO}_{2}$ nanoparticles result in a significantly higher aggregation due to their immiscibility, as shown in Fig. 2(d). The sizes of aggregated nanoparticles were measured up to $5 \mathrm{~mm}$. It can be concluded that the nanoparticles in the PCL polymer were not dispersed on a nano-scale. The intersurface interactions between the PCL polymer and nanoparticles, and also between the paperboard and nanoparticles are responsible for such variations in morphology. Because $\mathrm{Al}_{2} \mathrm{O}_{3}$ nanoparticles are not visible on the surface of the coating (Fig. 2(b)), it can be assumed that they form higher interactions with paperboard than with PCL, which results in the presented morphology. All changes in the PCL nanocomposite coatings morphology can reflect in the properties of the coated paperboard packaging, like mechanical properties, barrier properties, and changes in the print color, but despite such aggregation and due to the low concentration, this type of dispersion can still contribute to the enhancement of barrier and mechanical properties ${ }^{16}$.

\section{Water permeability}

PCL is known for good water vapor properties $^{5,17}$ but PCL paperboard coating modified with $\mathrm{Al}_{2} \mathrm{O}_{3}$ and $\mathrm{SiO}_{2}$ nanoparticles is not widely investigated. The percentage results of the WVTR in relation to the control (K/0 - neat paperboard) are presented in Fig. 4. The WVTR results of the control sample were defined as $100 \%$ and the other samples are presented in relation to those values. The results show that the PCL coating has a decrease in permeability $(15 \%)$. The sample with $\mathrm{PCL}-\mathrm{Al}_{2} \mathrm{O}_{3}$ $(\mathrm{K} / \mathrm{P} / 1 \mathrm{Al})$ coating also has a similar $(14 \%)$ decrease in water vapor transmission and does not show a higher decrease in permeability, even though $\mathrm{Al}_{2} \mathrm{O}_{3}$ is known for its ability to improve barrier performance of polymers ${ }^{18}$. PCL coating with $\mathrm{SiO}_{2}$ nanoparticles $(\mathrm{K} / \mathrm{P} / 2 \mathrm{Si})$ shows a better improvement in permeability (decrease by $19 \%$ ) after $48 \mathrm{~h}$ WVTR test. The $\mathrm{SiO}_{2}$ nanoparticles with dissociative mechanism of water vapor adsorption usually first form $\mathrm{Si}-\mathrm{OH}$ bonds creating a layer that slows down the process of permeability ${ }^{19}$. Also, polymer/ layered silicate nanocomposites are characterized by very strong enhancements of polymer barrier properties. This can be explained by the concept of tortuous paths. When impermeable nanoparticles are incorporated into a polymer, the permeating molecules are forced to wiggle around them in a random walk, and hence diffuse by a tortuous pathway. Rigid fillers are naturally resistant to straining due to their high moduli. Thus, when a softer matrix is reinforced with such fillers, the polymer becomes highly restrained mechanically. From this mechanism, it is evident that the larger the surface of the filler in contact with the polymer, the greater the reinforcing effect will be ${ }^{20}$. The lowest decrease in permeability is seen in samples with the combination of $\mathrm{SiO}_{2}$ and $\mathrm{Al}_{2} \mathrm{O}_{3}$. The obvious cause is the aggregation, seen in the SEM results, which is caused by the hydrophilic properties of $\mathrm{Al}_{2} \mathrm{O}_{3}$ and hydrophobic properties of $\mathrm{SiO}_{2}$. Nanoparticles tend to aggregate due to the van der Waals forces when they are forming large fractal structures in tens or hundreds of microns in size. Hence, such materials lack the potential advantages that nanocomposites can offer ${ }^{21}$.

\section{Colorimetry}

To validate the color changes, the spectral reflectance of full tones of cyan, magenta, yellow and black were measured for each sample and converted to CIEL $a b$ color space. The obtained $L a b$ values before and after applying the coating were implemented in $\Delta E_{00}(2)$ and the results are presented in Fig. 5.

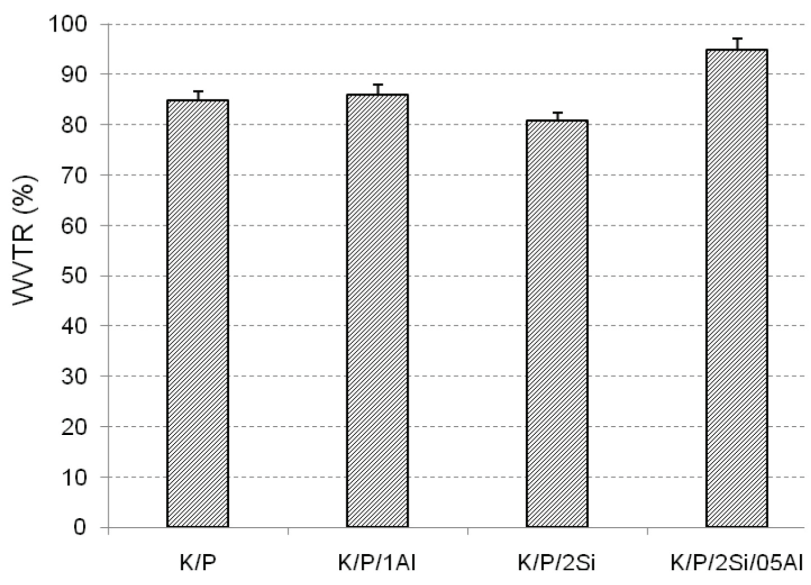

Fig. 4 - Water vapor transmission rates of PCL and PCL nanocomposite coated paperboards 


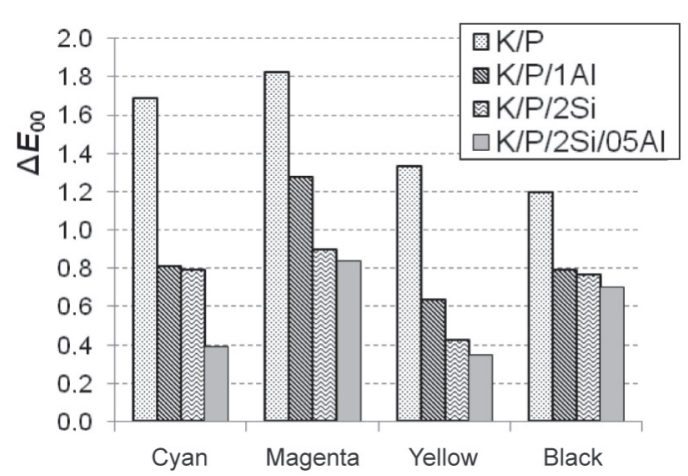

Fig. 5 - Color difference $\triangle E_{00}$ of cyan, magenta, yellow and black after PCL and PCL coating modified with $\mathrm{SiO}_{2}$ and $\mathrm{Al}_{2} \mathrm{O}_{3}$ nanoparticles

The greatest color difference appears in magenta tone for all coating samples, while the least color change is visible in yellow. Cyan and black tones have similar color differences. These values differ from the analysis of the spectral reflectance results ${ }^{22}$ because CIELab space and the $\Delta E_{00}$ compensate the color change perceivable by humans. This change and the $L a b$ values indicate that the PCL coating mostly influences the color lightness because the magenta color is the darkest when compared to cyan and yellow. Black is excluded because it is an achromatic color and has a different effect on human perception. This change in lightness is common for varnish type coatings ${ }^{23-26}$ especially when they have a mat and not glossy finish. The hue and chroma do not significantly differ.

Neat PCL coating results in a color change between 1.2 and $1.82 \Delta E_{00}$ which is also the highest of all tested samples. Humans usually perceive color change above $3 \Delta E_{00}{ }^{27}$ but this is a good indicator of the visual properties of coating samples and the effect of nanoparticles on PCL coatings. The samples with nanoparticles show a decrease in color difference approx. $50 \%$ and more, except PCL- $\mathrm{Al}_{2} \mathrm{O}_{3}$ sample for magenta tone. The decrease in color difference can be explained by the improvement of the refractive index of the PCL polymer after adding nanoparticles ${ }^{28}$. The least color change surprisingly appears in the PCL coating that is modified with the combination of nanoparticles. This is probably due to the synergistic effect that improves the refractive index of the coating despite the previously observed agglomerations.

\section{Mechanical properties}

One of the most representative tests for mechanical properties of paperboard is burst strength. It is determined by measuring the maximum pressure $(\mathrm{kPa})$ developed by the test device before tear occurrence in the paperboard sample. The burst strength results of the tested PCL coated paperboard samples are presented in Fig. 6. They show a small increase $(4.6 \mathrm{kPa})$ in burst strength for samples with pure PCL coating, while a better increase in bursting strength is visible for $\mathrm{K} / \mathrm{P} / 1 \mathrm{Al}(12.4 \mathrm{kPa})$ and $\mathrm{K} / \mathrm{P} / 2 \mathrm{Si}(12.8 \mathrm{kPa})$. The higher values of bursting strength show improvement of mechanical properties of the coated paperboard. Even though the thickness of the coated film is small in relation to paperboard $(2.1 \%)$, enhancements of mechanical properties are evident. This is due to implementation of $\mathrm{Al}_{2} \mathrm{O}_{3}$ and $\mathrm{SiO}_{2}$ nanoparticles, which improve toughness, mechanical strength and stiffness of a nanocomposite ${ }^{29}$. The sample with the combination of nanoparticles $\left(\mathrm{SiO}_{2} / \mathrm{Al}_{2} \mathrm{O}_{3}\right)$ shows results $(245.8 \mathrm{kPa})$ in-between neat PCL coated paperboard samples and samples with just one type of nanoparticles.

Fine particles tend to combine and form strongly bonded aggregates, which may further produce larger structures, agglomerates resulting in a nonhomogeneous surface. Another parameter that can affect the mechanical properties is the amount and nanoparticle shape of filler. For every filled polymer system there is a maximum volume fraction of particles that can be incorporated into the polymer matrix. Otherwise, it results in stress concentration points giving rise to a more brittle material with a lower ultimate tensile strength. The interfacial strength between filler and polymer is a very important factor, because lack of adhesion between the two phases will result in early failure. Other physical properties such as optical, magnetic, electronic, thermal, wear resistance, barrier to diffusion, water resistance or flame retardancy can be strongly affected by nanoparticle dispersion in polymer matrices. Regarding the biocomposites, nanoscale-organized composite with perfect dispersion provides a

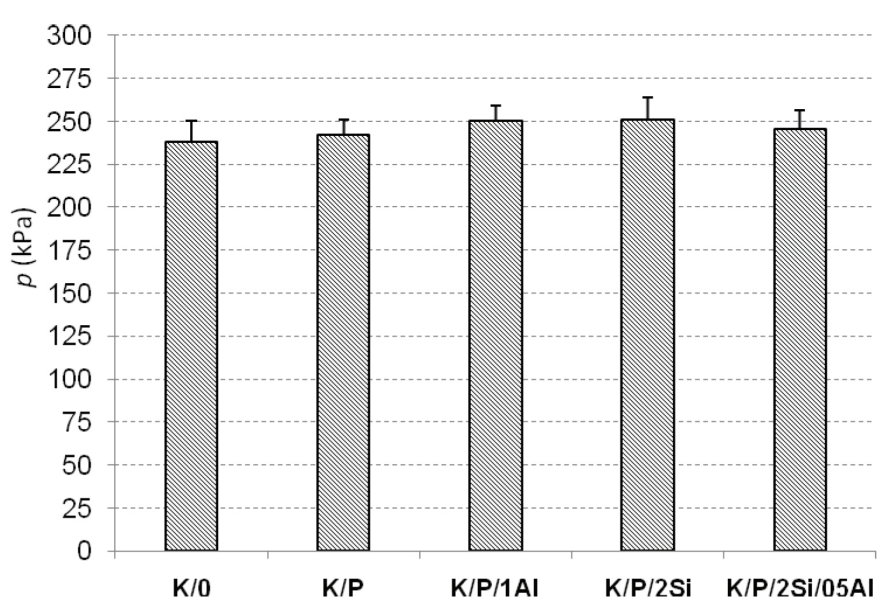

Fig. 6 - Burst strength of paperboard, PCL and PCL nanocomposite coated paperboards 
better substrate condition for cellular interaction, particularly in the cell adhesion and proliferation state, when compared with the conventional composite $^{30}$.

\section{Conclusions}

From the results presented in this paper, it can be concluded that:

- PCL coating decreases permeability of paperboard by $15 \%$, similar to PCL coating modified with 1 wt. $\% \mathrm{Al}_{2} \mathrm{O}_{3}$, while 2 wt. $\% \mathrm{SiO}_{2}$ in PCL coating improves WVTR by $19 \%$.

- Combination of $\mathrm{SiO}_{2}$ and $\mathrm{Al}_{2} \mathrm{O}_{3}$ in PCL coating causes agglomeration of nanoparticles and does not significantly decrease paperboard permeability.

- PCL coatings modified with $\mathrm{SiO}_{2}$ nanoparticles increase hydrophobic properties of GD2 paperboard.

- Water contact angle evolution over time indicates that PCL and PCL nanocomposite coatings reduce the absorption of water, hence reducing its wettability.

- Despite the high film to paperboard thickness ratio, PCL modified with 1 wt. $\% \mathrm{Al}_{2} \mathrm{O}_{3}$ or 2 wt.\% $\mathrm{SiO}_{2}$ slightly improves the burst strength properties of paperboard.

- When applying PCL and PCL $\left(\mathrm{Al}_{2} \mathrm{O}_{3}\right.$ and $\mathrm{SiO}_{2}$ ) nanocomposite coatings, most color differences appear in magenta colors.

- PCL modified with 2 wt.\% $\mathrm{SiO}_{2}$ and 0.5 wt. $\% \mathrm{Al}_{2} \mathrm{O}_{3}$ cause the least amount of color difference for full tones of primary offset colors.

An overall conclusion is that PCL polymer coating modified with $\mathrm{Al}_{2} \mathrm{O}_{3}$ and $\mathrm{SiO}_{2}$ nanoparticles can decrease paperboard permeability and improve mechanical properties of paperboard. Furthermore, implementation of nanoparticles improves the transparency (refractive index) of PCL coatings, which results in truer (more precise) color reproduction.

\section{References}

1. Cooper, T. A., Developments in Plastic Materials and Recycling Systems for Packaging Food, Beverages and Other Fast-Moving Consumer Goods, in Farmer, N. (Ed.), Trends in Packaging of Food, Beverages and Other Fast-Moving Consumer Goods (FMCG), Elsevier, Cambridge, UK, 2013, pp 58-107.

doi: https://doi.org/10.1533/9780857098979.58

2. Richard, C., Kirwan, M. J., Paper and Paperboard Packaging, in Richard, C., Kirwan, M. J. (Eds.), Food and Beverage Packaging Technology: Second Edition, Wiley-Blackwell, Oxford, UK, 2011, pp 213-250.

doi: http://doi.wiley.com/10.1002/9781444392180.ch8
3. Samyn, P., Deconinck, M., Schoukens, G., Stanssens, D. Vonck, L., Van Den Abbeele, H., Modifications of paper and paperboard surfaces with a nanostructured polymer coating, Prog. Org. Coatings 69 (2010) 442.

doi: https://doi.org/10.1016/j.porgcoat.2010.08.008

4. Hrnjak-Murgić, Z., Rešček, A., Ptiček Siročić, A., Kratofil Krehula, L., Katančić, Z., Polymer Nanocomposites with Water Vapour Permeability, in Nanoparticles in Active Polymer Food Packaging, Smithers Pira Technology Ltd, Shawbury, Shrewsbury, Shropshire, UK, 2015, pp 137-156.

5. Han, J., Salmieri, S., Le Tien, C., Lacroix, M., Improvement of water barrier property of paperboard by coating application with biodegradable polymers, J. Agric. Food Chem. 58 (2010) 3125 . doi: https://doi.org/10.1021/jf904443n

6. Li, Y., Han, C., Zhang, X., Bian, J., Han, L., Rheology, mechanical properties, and biodegradation of poly $(\varepsilon$-caprolactone)/silica nanocomposites, Polym. Compos. 34 (2013) 1620 .

doi: https://doi.org/10.1002/pc.22562

7. Avella, M., Bondioli, F., Cannillo, V., Di Pace, E., Errico, M. E., Ferrari, A. M., Focher, B., Malinconico, M., Poly(E-caprolactone)-based nanocomposites: influence of compatibilization on properties of poly( $\varepsilon$-caprolactone)silica nanocomposites, Compos. Sci. Technol. 66 (2006) 886. doi:https://doi.org/10.1016/j.compscitech.2005.08.014

8. Avella, M., Bondioli, F., Cannello, V., Cosco, S., Errico, M. E., Ferrari, A. M., Focher, B., Malinconico, M., Properties/ structure relationships in innovative PCL-SiO nanocomposites, Macromol. Symp. 218 (2004) 201. doi:https://doi.org/10.1002/masy.200451421

9. Lee, K. S., Chang, Y. W., Thermal and mechanical properties of poly(E-caprolactone)/polyhedral oligomeric silsesquioxane nanocomposites, Polym. Int. 62 (2013) 64. doi:https://doi.org/10.1002/pi.4309

10. Guillaume, M. D., Chivas-Joly, E., C., Properties of Nanofillers in Polymer, in Cuppoletti, $J$. (Ed.) Nanocomposites and Polymers with Analytical Methods, InTech, Shanghai, China, 2011, pp 261-284. doi:https://doi.org/10.5772/21694

11. Ribeiro, T., Baleizão, C., Farinha, J., Functional films from silica/polymer nanoparticles, Materials 7 (2014) 3881. doi: https://doi.org/10.3390/ma7053881

12. Paul, D. R., Robeson, L. M., Polymer nanotechnology: nanocomposites, Polymer 49 (2008) 3187. doi: https://doi.org/10.1016/j.polymer.2008.04.017

13. Gao, Z., Zhao, L., Effect of nano-fillers on the thermal conductivity of epoxy composites with micro- $\mathrm{Al}_{2} \mathrm{O}_{3}$ particles, Mater. Des. 66 (2015) 176.

doi: https://doi.org/10.1016/j.matdes.2014.10.052

14. Radusin, T. I., Pilić, B. M., Ristić, I. S., Bera, O. J., Baloš, $S$., The influence of silica nanoparticles on mechanical properties of polylactic acid as food packaging material, Food Feed Res. 39 (2012) 61.

link: http://fins.uns.ac.rs/e-journal/uploads/Magazines/ magazine 118/THE INFLUENCE OF SILICA

NANOPARTICLES_ON_MECHAN̄ICĀL PROPERTIES OF POLYLACTIC ACID AS FOOD PACKA $\bar{A}$ GING MATERIAL.pdf

15. Wang, H., Cui, G., Luo, M. R., Xu, H., Evaluation of colour-difference formulae for different colour-difference magnitudes, Color Res. Appl. 37 (2012) 316. doi: https://doi.org/10.1002/col.20693 
16. Chatterjee, S., Castro, M., Feller, J. F., An e-nose made of carbon nanotube based quantum resistive sensors for the detection of eighteen polar/nonpolar VOC biomarkers of lung cancer, J. Mater. Chem. B 1 (2013) 4563.

doi: https://doi.org/10.1039/c3tb20819b

17. Granado, L. M., Carr, L. G., Fernandes, L. L., Parra, D. F., Sato, J. S., Ademar, B., Marchini, L. G., Ponce, P., Permeability and Mechanical Properties of Pcl Films, in Proceedings of the World Polymer Congress - Macro 2006, 41st International Symposium on Macromolecule, Rio de Janeiro, Brasil (2006) https://www.ipen.br/biblioteca/2006/macro/11459.pdf

18. Struller, C. F., Kelly, P. J., Copeland, N. J., Aluminum oxide barrier coatings on polymer films for food packaging applications, Surf. Coatings Technol. 241 (2014) 130 doi: https://doi.org/10.1016/j.surfcoat.2013.08.011

19. Ayhan, Z., Potential Application of Nanomaterials in Food Packaging and Interactions of Nanomaterials with Food, in Silvestre, C., Cimmino, S., (Eds.) Ecosustainable Polymer Nanomaterials for Food Packaging, CRC Press, Boca Raton, USA, 2013, pp 253-280.

20. Pavlidou, S., Papaspyrides, C. D., A Review on polymerlayered silicate nanocomposites, Prog. Polym. Sci. 33 (2008) 1119. doi: https://doi.org/10.1016/j.progpolymsci.2008.07.008

21. To, D., Dave, R., Yin, X., Sundaresan, S., Deagglomeration of nanoparticle aggregates via rapid expansion of supercritical or high-pressure suspensions, AIChE J. 55 (2009) 2807. doi: https://doi.org/10.1002/aic.11887

22. Bota, J., Vukoje, M., Brozović, M., Hrnjak-Murgić, Z., Enhancement of Water Permeability of Biodegradable PCL Nanocomposite Coated Paperboard Packaging, in 4th Inter- national Symposium of Environmental Management - Towards Circular Economy, University of Zagreb, Faculty of Chemical Engineering and Technology, Zagreb, Croatia (2016) 180.

23. Simonot, L., Elias, M., Color change due to a varnish layer, Color Res. Appl. 29 (2004) 196. doi: https://doi.org/10.1002/col.20008

24. Day, C., The Optical Properties of Varnishes and Their Effects on Image Quality, Doctoral Thesis, Rochester Institute of Technology, 2001.

25. Majnarić, I., Golubović, K., Bolanča Mirković, I., New Methods of Varnishing and Their Influence on Optical Properties of Cardboard Packaging, in Conference proceedings MATRIB 2012, Hrvatsko društvo za materijale i tribologiju, Zagreb, Croatia (2012) 179.

26. Bota, J., Brozović, M., Hrnjak-Murgić, Z., Influence of Silica Nanoparticles in PCL Overprint Coating on the Color Change of Offset Print, in International Symposium on Graphic Engineering and Design GRID, Faculty of Technical Sciences, Novi Sad, Serbia (2014) 225.

27. Kipphan, H,. Print Quality, in Kipphan, H. (Ed.) Handbook of Print Media, Springer Berlin Heidelberg, Berlin, Heidelberg, Germany, 2001, pp 99-107.

28. Salamone, J. C., Polymeric Materials Encyclopedia, Salamone, J. C., Claypool, J., Demby (Eds.), Twelve Volume Set, CRC Press, Boca Raton, USA, 1996, pp 2218-2235.

29. Tjong, S. C., Structural and mechanical properties of polymer nanocomposites, Mater. Sci. Eng. R Reports 53 (2006) 73. doi: https://doi.org/10.1016/j.mser.2006.06.001

30. Šupová, M., Martynková, G. S., Barabaszová, K., Effect of nanofillers dispersion in polymer matrices: A review, Sci. Adv. Mater. 3 (2011) 1. 